\title{
Spherical Fuzzy WASPAS-based Entropy Objective Weighting for International Payment Method Selection
}

\section{Phi-Hung Nguyen ${ }^{1,2, *}$, Thanh-Tuan Dang ${ }^{3}$, Kim-Anh Nguyen ${ }^{1}$ and Hong-Anh Pham ${ }^{1}$}

\author{
${ }^{1}$ Faculty of Business, FPT University, Hanoi, 100000, Vietnam \\ ${ }^{2}$ Department of Business Management, National Taipei University of Technology, Taipei, 1068, Taiwan \\ ${ }^{3}$ Department of Industrial Engineering and Management, National Kaohsiung University of Science and Technology, \\ Kaohsiung, 80778, Taiwan \\ *Corresponding Author: Phi-Hung Nguyen. Email: hungnp30@fe.edu.vn \\ Received: 26 November 2021; Accepted: 14 January 2022
}

\begin{abstract}
In international trade, exporters prefer to receive payments as quickly as possible, and importers want to make payments as late as possible. In this respect, the payment field, an essential condition for trade transactions, also represents the positions of exporters and importers conflict. In addition, there are many cases in which various variables must be considered rather than only one specific variable representatively affecting payment, particularly in the case of import-export Small and Medium-Sized Enterprises (SMEs) from emerging countries. A selection of proper payment methods can be categorized as a Multi-Criteria Decision-Making (MCDM) issue. Therefore, this study aims to propose a novel and efficient Spherical Fuzzy Weighted Aggregated Sum Product Assessment based Entropy Objective Weighting method (SF-EW and WASPAS-SF) to evaluate international payment methods with uncertain information. First, SF-EW model is applied to determine the relative weights of critical factors. Second, international payment method alternatives are prioritized by the WASPAS-SF approach. Five essential factors for four international payment methods are proposed based on experts' opinions and the existing literature. A real-world case study from Vietnamese import-export SMEs is presented to validate the applicability of the proposed framework. The results indicated that "Characteristics of payment method (PA)" had the most significant impact on international payment method selection. In comparison, "Letters of Credit (L/C)" was the most reliable payment method with the highest ranking available to international traders. Furthermore, a sensitivity analysis was performed to examine the validity and robustness of the proposed decision support model. Consequently, this study could contribute to international payment services and in the context of globalization and international trade.
\end{abstract}

Keywords: International payment; Vietnam; MCDM; spherical fuzzy theory; entropy; WASPAS 


\section{Introduction}

In the current trend of globalization of the economy and international trade, the international payment activities of commercial banks are a vital component in the process of concluding a foreign trade agreement [1]. International payment activities also boost the bank's external relationships, increase its competitiveness, improve its international reputation, and, as a result, exploit funding sources from foreign banks and capital sources in the international financial market to meet the bank's capital needs.

In Vietnam, the banking system is divided into state banks and commercial banks. Currently, nine state-owned banks are divided into state-owned commercial banks, policy banks, and jointstock commercial banks with state capital more significant than $50 \%$, typically Vietcombank, Vietnam Development Bank, Agribank. Commercial banks based on ownership form will be divided into five types, including state-owned commercial banks, joint-stock commercial banks, joint venture banks, foreign banks based in Vietnam, and commercial banks with $100 \%$ capital overseas [2]. In international payments (IP), the banking services provided include export payments offered to exporters, import payments served to importers, and cross-border payment is a payment solution for businesses that buy and sell goods with Chinese partners [3].

For each IP method, the bank will have different obligations and responsibilities. For Cash in Advance and Open Account methods, the bank will act as a payment intermediary to transfer money to related parties. For Document Collection, the bank is both a payment intermediary and must send documents to the importer. For Letter of Credit (L/C), besides the above tasks, the bank must also ensure payment to the exporter and check the documents for any discrepancy decide to pay [4]. In recent years, the growth rate of international payment methods at Vietnamese commercial banks has changed significantly. According to statistics of several banks, the proportion by Cash in advance tends to increase, while the proportion of payment by L/C tends to decrease. Specifically, there are several principal forms of payment: international remittance, trade finance including $\mathrm{L} / \mathrm{C}$ and collection, and border payment [5]. The gradual shift to cash in advance payment can help businesses save costs compared to using safer payment methods through banks, such as collecting documents and paying by $\mathrm{L} / \mathrm{C}$. The Vietnamese importer had to ask the bank to issue the $\mathrm{L} / \mathrm{C}$, even a confirmed $\mathrm{L} / \mathrm{C}$ for payment from the initial distrust. Analysis of the current situation of using international payment methods at Vietnamese commercial banks shows that using money transfer and collection is increasing. The payment method by L/C tends to decrease shortly.

However, there are several intricacies regarding the geographical distance between the parties, differences in time zones, and currencies. This has resulted in the development of specialized payment methods to cater to the needs of international payments [6]. Recognizing and avoiding biased judgments and choices during the choosing process of international payment methods is not an easy undertaking for decision-makers (DMs) because of involves many potential criteria. Multi-criteria decision-making (MCDM) procedures are unquestionably beneficial for boosting the dependability of selections and reducing the subjective nature of made decisions [7]. It is vital to develop decisionmaking tools and procedures that can deal with this level of complexity. MCDM techniques facilitate the evaluation and selection of the optimal alternative based on a set of criteria.

Among popular MCDM models, entropy is simpler and more suitable for criteria with strong independence than similar weighting methods like the maximum deviation method and correlation coefficient method [8]. The WASPAS method has been applied in various real-world problems. WASPAS is known as an integration of simple additive weighting (SAW) and weighted product model $(\mathrm{WPM})$ through $(\lambda)$ parameter and therefore, it is the fact that a joint generalized criterion of weighted 
aggregation of the methods increases the ranking reliability [9]. Compared to other methods, WASPAS is a relatively novel and straightforward MCDM method that has been widely expanded in various doctrines. In addition to its simplicity, WASPAS uses the concept of ranking accuracy and is more accurate than WSM and WPM. To reduce imprecise information and vague judgments, there have been various extensions of WASPAS with numerous developments of fuzzy sets, which are widely employed in the literature. Even though numerous studies have utilized MCDM models and Spherical fuzzy sets to address real-world problems, no study has applied the Entropy and WASPAS framework to prioritize international payment methods in emerging markets countries. Therefore, the main objective of this study is to propose a practical approach for evaluating and selecting international payment methods under uncertain business environments. This research is conducted by identifying critical factors of international payment methods in import-export activities in the context of Vietnamese SMEs and ranking international payment methods using a novel MCDM framework-based Spherical fuzzy set.

The contributions are three-fold in this study. First, this research aims to construct a robust integration of SF-EW and WASPAS-SF to support stakeholders of import-export SMEs in selecting international payment methods. All critical criteria affecting the selection process of international payment methods were defined by experts' opinions and based on the literature review. The SF-EW was utilized to calculate criteria weights under uncertain circumstances and qualitative judgments. The WASPAS method ranked all widely used methods in terms of international payment. The implementation, via the use of a case study, demonstrates the feasibility of the proposed paradigm. Additionally, the combined model can be investigated in conjunction with other models to broaden the range of outcomes. The suggested Spherical fuzzy MCDM model will aid academics and decision-makers in determining the ideal payment service in international trade while considering critical factors. Additionally, the prescribed approach and outcomes in this study can inform similar international payment method selection processes in other nations and businesses.

\section{Literature Review}

\subsection{Literature Review on MCDM Methods}

Many attempts in the realm of international trade have been made. Receiving payments against export from the overseas buyer on time is a requirement for sustainable export. The form of payment utilized for a particular transaction has an enormous impact on whether the payment is received on time. Other factors can also have an impact on payment. The most essential is the possible risk and expense that the exporters and importers are willing to incur or share. Various extensions, such as Pythagorean fuzzy sets, intuitionistic fuzzy sets, neutrosophic sets, hesitant fuzzy sets, and so on, are developed in the literature to address the shortcomings of existing definitions of fuzzy sets. The entropy weighting approach is used to derive objective weights of decision qualities or the importance of DMs indicating their level of expertise. They are helpful when subjective weight evaluation is not sought or required. It is demonstrated that the WASPAS-SF technique based on the entropy method is highly robust because the novel entropy measure does not often produce an undesirable ranking solution. Wang [10] proposed combining the Decision-Making Trial and Evaluation Laboratory Technique (DEMATEL) with the Analytic Network Process (ANP) to handle dependence and feedback difficulties and to choose an acceptable international interactive trade. Chiao et al. [11] used the fuzzy analytic hierarchy process (FAHP) to evaluate account receivable collection instruments by examining four collection alternatives: L/C, Documentary collection, Prepayment, and Open Account in the case of Taiwan. Recently, Surucu-Balci [12] utilized interpretative structural modeling and 
Cross-Impact Matrix Multiplication Applied to Classification analyses to investigate the relationships between blockchain adoption barriers and identify the critical stakeholders for blockchain adoption in containerized international trade. A few research, however, used the WASPAS technique in their analyses. Lescauskiene et al. [13] introduced VASMA weighting with WASPAS-SVNS integration to discover subjective weights and entropy for objective weights. Kutlu Gündoğdu et al. [14] proposed extending the classic WASPAS approach to the spherical fuzzy WASPAS (WASPAS-SF) method and applying it to an industrial robot selection problem. Ayyildiz et al. [15] applied the spherical fuzzy AHP-integrated spherical WASPAS method to determine the optimal petrol station location in the case of Istanbul. Keshavarz-Ghorabaee et al. [16] developed a novel system for evaluating green building suppliers based on WASPAS, SMART, and Fermatean fuzzy sets. Nguyen et al. [17] applied a hybrid Spherical Fuzzy AHP and Fuzzy WASPAS model to assist stakeholders such as governors and policymakers in prioritizing governmental interventions in response to the COVID-19 epidemic. Gul et al. [18] introduced a modified failure modes and effects analysis using the interval-valued spherical fuzzy extension of technique for order preference by similarity to ideal solution (TOPSIS) method, with a case study in a marble manufacturing facility. Sharaf et al. [19] proposed a spherical fuzzy TODIM (an acronym in Portuguese for iterative MCDM) for green occupational health and safety equipment supplier selection. Bakır et al. [20] employed an integrated fuzzy Pivot Pairwise Relative Criteria Importance Assessment (F-PIPRECIA) and fuzzy Measurement Alternatives and Ranking according to the Compromise Solution (F-MARCOS) approach for the regional aircraft selection with a case study of the Turkish airline industry.

To summarize, there is a lack of MCDM applications in general, precisely the spherical fuzzy entropy-based WASPAS-SF method in studying international trade and payment methods, and a lack of studies on factors influencing payment terms choice of ranking methods for payment terms selection. To the best of our knowledge, there is no study using a combination of Entropy and WASPAS based Spherical fuzzy to solve the MCDM problems in the case of international trade, particularly in the context of import-export SMEs from Vietnam. Aside from the fact that selection criteria for foreign payment methods are qualitative, articulating criteria for a method's capabilities in different values is tricky. This work aims to fill a research gap by using an MCDM technique with Spherical fuzzy sets to find relevant elements of international payment methods. Beyond that, we propose rankings of payment methods to assist Vietnamese import-export businesses in determining the appropriate payment options. The proposed extension approach is used with spherical fuzzy numbers in this study. So far, no evidence of the SF-EW and WASPAS studies' usefulness in the field of international payment method selection has been produced. This conclusion suggests that the proposed method's capabilities could be tested in import-export activities and other sectors.

\subsection{Literature Review on International Payment Methods}

The choice of international payment methods will directly affect the interests of exporters and importers. Therefore, for international trade and international payments, businesses need to research their partners before transacting carefully, and businesses must consider carefully before choosing a payment method fit. Risks in international payment activities are economic risks arising in conducting international payment activities. Many factors can happen between when a transaction is completed and when the money is expected to be received, making international transactions less stable, safe, transparent, or reliable than domestic transactions [21]. It occurs due to causes arising from the relationship between the parties to international trade (exporters, importers, banks, organizations, individuals, and intermediaries). Like risks in domestic, commercial transactions, but more complicated due to geographical distance, differences in culture, laws. Recently, Hoefele et al. [22] 
empirically investigated the selection of different payment alternatives by using firm-level data from developing nations. Their findings showed that payments are made after delivery when financing costs are high and contract enforcement is low in the source country. Also, it has been proved that industry complexities could influence the importance of contract enforcement and financing costs when making a contract choice. Based on a comprehensive literature review, Binet et al. [23] established a framework for qualifying payment in international trade. The agreement's subsequent findings indicated that it might be viewed as a payment for ecosystem services. The EU spent money to conserve local fish resources that its fishing fleet could exploit.

Moreover, it paves the way for further payment applications for ecosystem service schemes in various ecosystem contexts and is a valuable alternative source of funding for marine biodiversity conservation. Hwang et al. [24] examined factors affecting the significant change in export payment terms in Korea from 1997 to 2015. The study concluded that growing global competitiveness, higher exports of information technology products and intra-firm trade, and developments in information and communication technology would all result in a decline in the share of $\mathrm{L} / \mathrm{C}$ terms in overall exports over the long run. Zhou et al. [25] discussed global payment risks in private SMEs in Zheijiang, China, investigating the reasons for increasing international payment risks from a cultural perspective, then offered recommendations for the better management of payment risks during the post-crisis period.

Document collection method $(X 1)$ : It is more advantageous for the exporter because the bank has taken over the role of the exporter in controlling the items through documentation. The importer must pay or agree to pay to receive the necessary documentation to receive the goods [26]. Documentary collections are more convenient to use than Letters of Credit, and bank fees are typically lower. However, this method has the disadvantages of not guaranteeing the seller's interests because the payment depends on the buyer's wishes and slow payment speed. The banks act merely as intermediaries to facilitate payment for a shipment [27].

Open account method (X2): It is entirely beneficial for the importer, who only must pay when the goods or services have been received or even when the goods and services have been consumed. The exporter shall bear the risk of delay in payment or incomplete payment by the importing party. The seller's capital is stagnant until the buyer receives the goods, sometimes encountering the buyer's non-payment because the buyer did not need to issue any promissory notes in the first instance [28].

Letters of credit method (X3): In international goods sale and purchase activities, the payment method of letter of credit has transferred the payment responsibility from the importer to the bank to ensure that the exporter delivers and receives money safely quickly. Importers receive the shipping invoice on time [29]. Therefore, to a certain extent, $\mathrm{L} / \mathrm{C}$ is a payment method that balances the interests of both exporters and importers and resolves conflicts of distrust of both parties. However, in applying the Letters of Credit method, there are still some risks for import and export enterprises. In case the exporter presents a set of documents that do not conform to the $\mathrm{L} / \mathrm{C}$, any payment may be refused, and the exporter will have to deal with it himself by uploading, storing, and auctioning, etc., until the problem is resolved, or the goods must be shipped back to the country. The exporter must pay overdue storage, storage fees, insurance for goods, etc. Besides, the bank only checks for the apparent validity of such documents; there is no guarantee to the importer that the goods will be by the contract in quantity, type and undamaged, etc. In this case, the importer still must refund the total amount paid to the issuing bank.

Cash in advance method (X4): This is regarded as the most secure and risk-free mode of international commerce for the seller, as money is received before dispatch. However, it will be very disadvantageous to the buyer if the money transfer is completed, the seller goes bankrupt or delivers 
the goods with the wrong quantity, type, poor quality, or does not guarantee the delivery time as agreed [30]. The importer rarely chooses cash in advance unless the seller is fortunate, has unique or high-demand products, or the buyer is unknown from an unstable country.

\subsection{Proposed Criteria Affecting Payment Method Selection in International Trade}

Numerous studies describe international trade. However, research on the factors affecting the decision to choose a payment method is quite modest. First, Petersen [31] showed that the criteria related to the relationship between importers and exporters should be evaluated. This criterion is also considered by Agbonika [32], and the author further highlighted another important aspect, namely product characteristics. Becker [33] indicated that businesses should consider carefully when choosing a payment method for custom-made items that are specialized goods. For example, suppose this is one of the unique products, not for everyone. In that case, it is difficult for businesses to find alternative partners when the importer refuses to receive the goods using documentary collections.

On the other hand, when analyzing payment methods for importers, Laurel Delaney [34] pointed out that for this factor, businesses should consider more about product consumption in the country they import, whether customer demand is significant or not. As such, exporters may be willing to be more flexible with payment terms. Specifically, the exporter can allow the importer to pay a part in advance or extend the payment period if a potential partner needs time to recover capital when processing a large shipment. Aside from the item's quality, the value of the transaction is also mentioned. In this study, five critical criteria are proposed based on the literature review and experts' opinions in the context of Vietnamese import-export SMEs.

Type of goods (GO): Depending on the type of import and export goods, enterprises will choose different payment methods following their specific characteristics. Businesses can consider simple payment methods for goods that are easy to trade on the market. The complicated nature of commodities, on the other hand, has an impact on the decision to choose the method of enterprise [35]. For items with a high level of intricacy (i.e., machinery and equipment, production lines), sometimes it is necessary to use binding methods or mix different methods. In addition, the parties also need to understand the value of the shipment; if the shipment is of high value, it is also necessary to use payment methods with high safety and low risk. Furthermore, the seasonality of the product and the preferences of the consumer should be considered. Specifically, suppose the delay in the transaction time can affect the quality of the goods. In that case, the importer will consider choosing a method with guaranteed delivery time, or if the product has an essential change in price in the market, the field will make the parties decide to choose a complex and highly secure method.

Opinions and requirements of external parties ( $E X)$ : External parties impact companies as they decide which international payment method to use. Specifically, companies know that the bank is a neutral third party with sufficient expertise and experience to choose an appropriate payment method. As a result, the bank will provide guidance and suggestions during trade, significantly affecting the trader's judgment [36]. In terms of other aspects, although the import-export trader decides the payment method, it is not always accepted by the bank because the customer does not meet some bank regulations. Typically, about credit requirements, if their business wants to open an $\mathrm{L} / \mathrm{C}$, but currently the credit requirements of the business cannot be met, it cannot open an $\mathrm{L} / \mathrm{C}$, the import-export trader must switch to another payment method [37].

Political-economic situation of partner $(M A)$ : Import and export is a typical activity in foreign trade; one country and another will exchange goods or services. Every foreign market has its characteristics. Therefore, the parties need to raise questions about the political and economic conditions within 
the importer and exporter's nationals [38]. When conducting international trade, the parties need to pay attention to the political situation in each country. Issues related to import and export policies, or tariff barriers should be carefully considered. Moreover, increased import and export activities create great value of goods and materials for each country. Based on tax policies, tax collection from these import and export activities also increases over time, playing a significant role in the state budget. In addition, the economic growth rates of different countries vary significantly [30].

Relationship between the two parties $(R E)$ : The relationship between the exporter and the importer is built on the time and frequency of cooperation; the reliability will be high if the two parties have had a long-term cooperation relationship or if the two parties have never incurred any violations in the payment or delivery process in the previous cooperation process [38]. Clients with a high reputation level may also give their partners a certain amount of trust when dealing with new customers. From the standpoint of the exporter, with a low degree of trust, usually choose the method of cash in advance or documentary credit to ensure payment to avoid the possibility of the buyer misappropriating the seller's capital during the payment process, the buyer misappropriated the seller's capital, slows down, or lacks payment, even refuses to pay. Thus, it is critical to carefully analyze the payment options available to reduce payment risk for organizations [31].

Characteristics of each payment method (PA): When choosing a suitable payment method for businesses, the characteristics of each method are a factor that businesses cannot ignore [39]. Because each method has its advantages and disadvantages, characteristics for each party, however, common issues can be mentioned, such as the cost when choosing this method, the level of risk faced, the interests of the transaction participants are guaranteed or not or the speed of payment processing when using this method. These characteristics all influence the choice decision of the business [38].

\section{Methodology}

\subsection{Basic Operations of Spherical Fuzzy Sets}

Kutlu Gündouğdu et al. [40] suggested Spherical Fuzzy Sets (SFS) as the newest development of the fuzzy sets with each spherical fuzzy number including the membership, non-membership, and hesitancy function belonging to the interval [0,1] (Fig. 1).

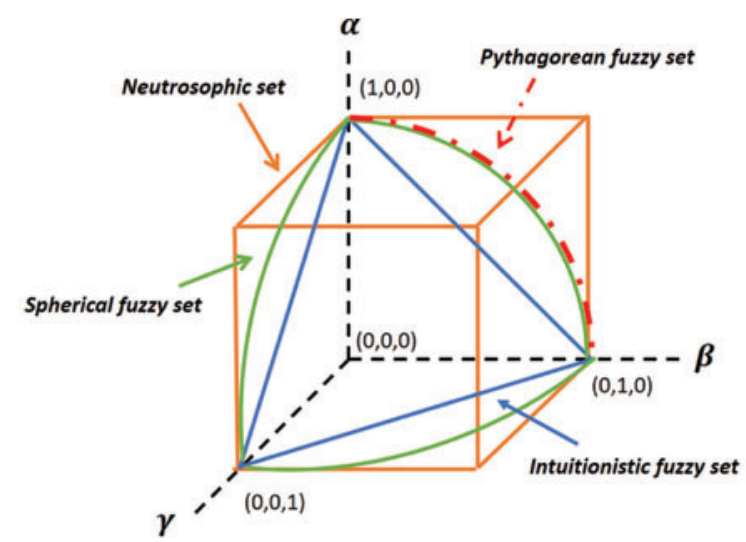

Geometric representations of IFS, PFS, NS, and SFS

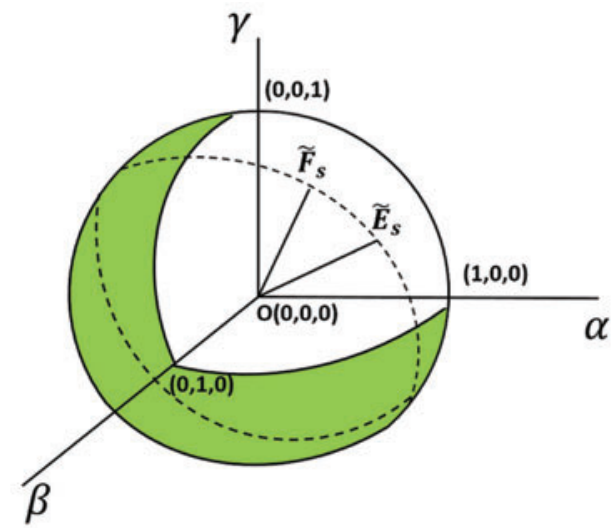

Geometrical representation of spherical fuzzy sets

Figure 1: Geometric representations of SFS 
Definition 1: SFS is presented as $\tilde{F}_{S}$ :

$\tilde{F}_{S}=\left\{x,\left(\alpha_{\tilde{F}_{S}}(x), \beta_{\tilde{F}_{S}}(x), \gamma_{\tilde{F}_{S}}(x)\right) \mid x \in X\right\}$

where $\tilde{F}_{S}$ denotes a spherical fuzzy set of the universe $X$.

$\alpha_{\tilde{F}_{S}}(x): X \rightarrow[0,1], \beta_{\tilde{F}_{S}}(x): X \rightarrow[0,1], \gamma_{\tilde{F}_{S}}(x): X \rightarrow[0,1]$

$0 \leq \alpha_{\tilde{F}_{S}}^{2}(x)+\beta_{\tilde{F}_{S}}^{2}(x)+\gamma_{\tilde{F}_{S}}^{2}(x) \leq 1$

with $\forall x \in X$, for each $x, \alpha_{\tilde{F}_{S}}(x), \beta_{\tilde{F}_{S}}(x)$ and $\gamma_{\tilde{F}_{S}}(x)$ denote for membership, non-membership, and hesitancy levels of $x$ to $\tilde{F}_{S}$, respectively.

Definition 2: Let $\tilde{F}_{S}=\left(\alpha_{\tilde{F}_{S}}, \beta_{\tilde{F}_{S}}, \gamma_{\tilde{F}_{S}}\right)$ and $\tilde{E}_{S}=\left(\alpha_{\tilde{E}_{S}}, \beta_{\tilde{E}_{S}}, \gamma_{\tilde{E}_{S}}\right)$ be two SFSs. Some arithmetic operations of SFS are presented as follows.

Union

$$
\begin{aligned}
\tilde{F}_{S} \cup \tilde{E}_{S} & =\left\{\max \left\{\alpha_{\tilde{F}_{S}}, \alpha_{\tilde{E}_{S}}\right\}, \min \left\{\beta_{\tilde{F}_{S}}, \beta_{\tilde{E}_{S}}\right\}, \min \left\{\left(1-\left(\left(\max \left\{\alpha_{\tilde{F}_{S}}, \alpha_{\tilde{E}_{S}}\right\}\right)^{2}\right.\right.\right.\right. \\
& \left.\left.\left.\left.+\left(\min \left\{\beta_{\tilde{F}_{S}}, \beta_{\tilde{E}_{S}}\right\}\right)^{2}\right)\right)^{0.5}, \max \left\{\gamma_{\tilde{F}_{S}}, \gamma_{\tilde{E}_{S}}\right\}\right\}\right\}
\end{aligned}
$$

Intersection

$$
\begin{aligned}
\tilde{F}_{S} \cap \tilde{E}_{S} & =\left\{\min \left\{\alpha_{\tilde{F}_{S}}, \alpha_{\tilde{E}_{S}}\right\}, \max \left\{\beta_{\tilde{F}_{S}}, \beta_{\tilde{E}_{S}}\right\}, \max \left\{\left(1-\left(\left(\min \left\{\alpha_{\tilde{F}_{S}}, \alpha_{\tilde{E}_{S}}\right\}\right)^{2}\right.\right.\right.\right. \\
& \left.\left.\left.\left.+\left(\max \left\{\beta_{\tilde{F}_{S}}, \beta_{\tilde{E}_{S}}\right\}\right)^{2}\right)\right)^{1 / 2}, \min \left\{\gamma_{\tilde{F}_{S}}, \gamma_{\tilde{E}_{S}}\right\}\right\}\right\}
\end{aligned}
$$

Addition

$\tilde{F}_{S} \oplus \tilde{E}_{S}=\left\{\left(\alpha_{\tilde{F}_{S}}^{2}+\alpha_{\tilde{E}_{S}}^{2}-\alpha_{\tilde{F}_{S}}^{2} \alpha_{\tilde{E}_{S}}^{2}\right)^{0.5}, \beta_{\tilde{F}_{S}} \beta_{\tilde{E}_{S}},\left(\left(1-\alpha_{\tilde{E}_{S}}^{2}\right) \gamma_{\tilde{F}_{S}}^{2}+\left(1-\alpha_{\tilde{F}_{S}}^{2}\right) \gamma_{\tilde{E}_{S}}^{2}-\gamma_{\tilde{F}_{S}}^{2} \gamma_{\tilde{E}_{S}}^{2}\right)^{0.5}\right\}$

Multiplication

$\left.\left.\tilde{F}_{S} \otimes \tilde{E}_{S}=\left\{\alpha_{\tilde{F}_{S}} \alpha_{\tilde{E}_{S}},\left[\left(\left(\beta_{\tilde{F}_{S}}\right)^{2}+\beta_{(} \tilde{E}_{S}\right)^{2}-\beta_{(} \tilde{F}_{S}\right)^{2} \beta_{(} \tilde{E}_{S}^{2}\right)\right)\right]^{0.5},\left[\left(\left(1-\beta_{\tilde{E}_{S}}\right)^{2}\right) \gamma_{(} \tilde{F}_{S}\right)^{2}$

$$
\left.\left.\left.\left.\left.\left.+\left(1-\beta_{(} \tilde{F}_{S}\right)^{2}\right) \gamma_{(} \tilde{E}_{S}\right)^{2}-\gamma_{(} \tilde{F}_{S}\right)^{2} \gamma_{(} \tilde{E}_{S}^{2}\right)\right]^{0.5}\right\}
$$

Multiplication by a scalar; $\sigma>0$

$\sigma . \tilde{F}_{S}=\left\{\left(1-\left(1-\alpha_{\tilde{F}_{S}}^{2}\right)^{\sigma}\right)^{0.5}, \beta_{\tilde{F}_{S}}^{\sigma},\left(\left(1-\alpha_{\tilde{F}_{S}}^{2}\right)^{\sigma}-\left(1-\alpha_{\tilde{F}_{S}}^{2}-\gamma_{\tilde{F}_{S}}^{2}\right)^{\sigma}\right)^{0.5}\right\}$

Power of $\mathrm{F}_{S} ; \sigma>0$

$\tilde{F}_{S}^{\sigma}=\left\{\alpha_{\tilde{F}_{S}}^{\sigma},\left(1-\left(1-\beta_{\tilde{F}_{S}}^{2}\right)^{\sigma}\right)^{0.5},\left(\left(1-\beta_{\tilde{F}_{S}}^{2}\right)^{\sigma}-\left(1-\beta_{F_{S}}^{2}-\gamma_{\tilde{F}_{S}}^{2}\right)^{\sigma}\right)^{0.5}\right\}$

Definition 3: For these SFSs $\tilde{F}_{S}=\left(\alpha_{\tilde{F}_{S}}, \beta_{\tilde{F}_{S}}, \gamma_{\tilde{F}_{S}}\right)$ and $\tilde{E}_{S}=\left(\alpha_{\tilde{E}_{S}}, \beta_{\tilde{E}_{S}}, \gamma_{\tilde{E}_{S}}\right)$, the followings are valid under the condition $\sigma, \sigma_{1}, \sigma_{2}>0$.

$\tilde{\mathrm{F}}_{\mathrm{S}} \oplus \tilde{\mathrm{E}}_{\mathrm{S}}=\tilde{\mathrm{E}}_{\mathrm{S}} \oplus \tilde{\mathrm{F}}_{\mathrm{S}}$

$\tilde{\mathrm{F}}_{\mathrm{S}} \otimes \tilde{\mathrm{E}}_{\mathrm{S}}=\tilde{\mathrm{E}}_{\mathrm{S}} \otimes \tilde{\mathrm{F}}_{\mathrm{S}}$

$\sigma\left(\tilde{\mathrm{F}}_{\mathrm{S}} \oplus \tilde{\mathrm{E}}_{\mathrm{S}}\right)=\sigma \tilde{\mathrm{F}}_{\mathrm{S}} \oplus \sigma \tilde{\mathrm{E}}_{\mathrm{S}}$

$\sigma_{1} \tilde{\mathrm{F}}_{\mathrm{S}} \oplus \sigma_{2} \tilde{\mathrm{F}}_{\mathrm{S}}=\left(\sigma_{1}+\sigma_{2}\right) \tilde{\mathrm{F}}_{\mathrm{S}}$ 
$\left(\tilde{\mathrm{F}}_{\mathrm{S}} \otimes \tilde{\mathrm{E}}_{\mathrm{S}}\right)^{\sigma}=\tilde{\mathrm{F}}_{\mathrm{S}}^{\sigma} \otimes \tilde{\mathrm{E}}_{\mathrm{S}}^{\sigma}$

$\tilde{\mathrm{F}}_{\mathrm{S}}^{\sigma_{1}} \otimes \tilde{\mathrm{F}}_{\mathrm{S}}^{\sigma_{2}}=\tilde{\mathrm{F}}_{\mathrm{S}}^{\sigma_{1}+\sigma_{2}}$

Definition 4: Spherical weighted arithmetic mean (SWAM) concerning $w=\left(w_{1}, w_{2}, \ldots, w_{n}\right) ; w_{i} \in$ $[0,1] ; \sum_{i=1}^{n} w_{i}=1$, SWAM is defined as follows.

$$
\begin{aligned}
\operatorname{SWAM}_{w}\left(\tilde{F}_{S 1}, \ldots, \tilde{F}_{S n}\right)= & w_{1} \tilde{F}_{S 1}+w_{2} \tilde{F}_{S 2}+\ldots+w_{n} \tilde{F}_{S n}=\left\{\left[1-\prod_{i=1}^{n}\left(1-\alpha_{\tilde{F}_{S i}}^{2}\right)^{w_{i}}\right]^{0.5}, \prod_{i=1}^{n} \beta_{\tilde{F}_{S i}}^{w_{i}},\right. \\
& {\left.\left[\prod_{i=1}^{n}\left(1-\alpha_{\tilde{F}_{S i}}^{2}\right)^{w_{i}}-\prod_{i=1}^{n}\left(1-\alpha_{\tilde{F}_{S i}}^{2}-\gamma_{\tilde{F}_{S i}}^{2}\right)^{w_{i}}\right]^{0.5}\right\} }
\end{aligned}
$$

Definition 5: Spherical weighted geometric mean (SWGM) concerning $w=\left(w_{1}, w_{2} \ldots, w_{n} ; w_{i} \in\right.$ $[0,1] ; \sum_{i=1}^{n} w_{i}=1$, SWGM is defined as follows.

$$
\begin{aligned}
& \operatorname{SWGM}_{w}\left(\tilde{F}_{S 1}, \ldots, \ddot{F}_{S n}\right)=\tilde{F}_{S 1}^{w_{1}}+\tilde{F}_{S 2}^{w_{2}}+\ldots+\tilde{F}_{S n}^{w_{n}}=\prod_{i=1}^{n} \alpha_{\tilde{F}_{S i}}^{w_{i}}\left[1-\prod_{i=1}^{n}\left(1-\beta_{\tilde{F}_{S i}}^{2}\right)^{w_{i}}\right]^{0.5}, \\
& {\left[\prod_{i=1}^{n}\left(1-\beta_{\tilde{F}_{S i}}^{2}\right)^{w_{i}}-\prod_{i=1}^{n}\left(1-\beta_{\tilde{F}_{S i}}^{2}-\gamma_{\tilde{F}_{S i}}^{2}\right)^{w_{i}}\right]^{0.5} }
\end{aligned}
$$

Definition 6: Let $\tilde{F}_{s}$ and $\tilde{E}_{s}$ be two SFSs on $X$. A real-valued function EW: [0,1] SFS $\rightarrow$ is an entropy measure for SFSs if it is provided with the following properties:

$E W\left(\tilde{F}_{s}\right)=0$ if $\tilde{F}_{s}$ is a crispset,

$E W\left(\tilde{F}_{s}\right)=1$ if $\alpha_{\tilde{F}_{s}}(x)=\beta_{\tilde{F}_{s}}(x)$ and $\gamma_{\tilde{F}_{s}}(x)=0.5$ for all $x \in X$,

$E W\left(\tilde{F}_{s}\right)=E W\left(\tilde{F}_{s}^{c}\right)$, where $\tilde{F}_{s}^{c}$ denotes a compliment of $\tilde{F}_{s}$

$$
E W\left(\tilde{F}_{s}\right) \leq E W\left(\tilde{E}_{s}\right) \text { if } \gamma_{\tilde{E}_{s}}^{2}(x) \leq \gamma_{\tilde{F}_{s}}^{2}(x) \text { and } \alpha_{\tilde{F}_{s}}^{2}(x) \leq \alpha_{\tilde{E}_{s}}^{2}(x) \leq \beta_{\tilde{E}_{s}}^{2}(x) \leq \beta_{\tilde{F}_{s}}^{2}(x) \operatorname{or} \beta_{\tilde{F}_{s}}^{2}
$$

$$
(x) \leq \beta_{\tilde{E}_{S}}^{2}(x) \leq \alpha_{\tilde{E}_{S}}^{2}(x) \leq \alpha_{\tilde{F}_{S}}^{2}(x) \text { for all } x \in X .
$$

\subsection{Proposed Methodology}

The proposed method of SF-EW and WASPAS-SF is presented in Fig. 2. In this framework, we have three phases.

Phase I: A panel of decision-makers (DMs) is created by finding knowledgeable-experienced individuals in the context of the research scope to get their opinions and comments on criteria and alternatives of methods of international payment. And then, we prioritize the importance of experts based on their experiences.

Phase II: Differentiating from the previous study of [14], we applied the entropy weighting method extension of the spherical fuzzy set proposed by [41]. 
Phase III: The WASPAS model was firstly proposed by [42]. In this study, the spherical fuzzy extension of WASPAS (WASPAS-SF) using linguistic terms was proposed to overcome vague and imprecise assessments in the case of selecting international payment methods.

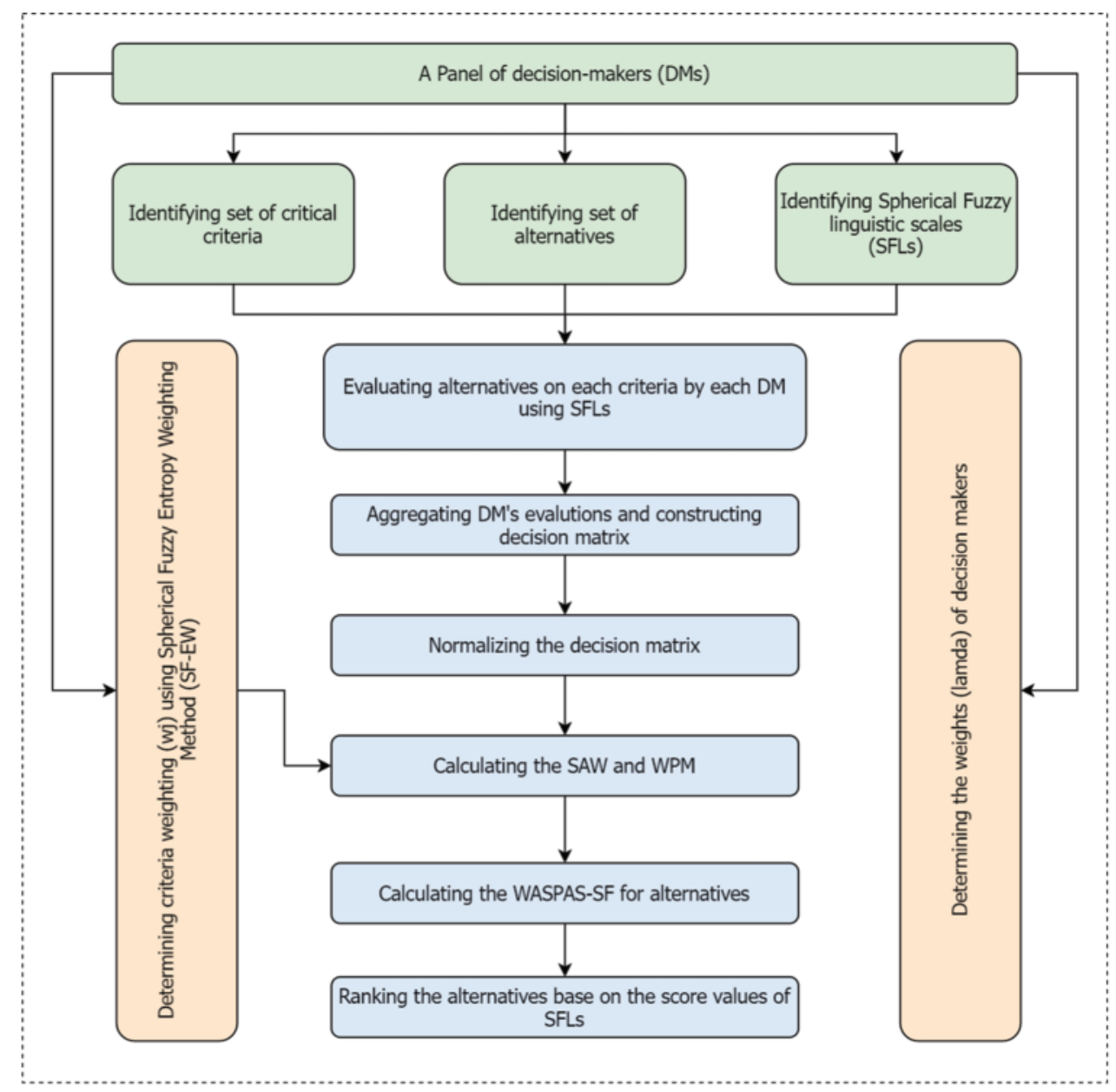

Figure 2: The proposed research framework

The process of the research is described as following steps to simplify the computing procedure [41]:

Step 1: Creating a pane of decision-makers (DMs) $e_{i}$. The spherical fuzzy number $e_{i}=\left[\alpha_{e_{i}}, \beta_{e_{i}}, \gamma_{e_{i}}\right]$ is denoted the rate of $i^{t h}$ DMs. The weight of $i^{\text {th }}$ DMs can be calculated using Eq. (19):

$\lambda_{e_{i}}=\frac{\left(\alpha_{e_{i}}+\gamma_{e_{i}}\left(\frac{\alpha_{e_{i}}}{\alpha_{e_{i}+\beta e_{i}}}\right)\right)}{\sum_{e=1}^{l}\left(\alpha_{e_{i}}+\gamma_{e_{i}}\left(\frac{\alpha_{e_{i}}}{\alpha_{e_{i}}+\beta_{e_{i}}}\right)\right)}$

Step 2: Employing entropy objective weights. DMs fulfill the criteria and alternative evaluation matrices $\left(\tilde{\mathrm{F}}_{\mathrm{S} 1}, \ldots, \tilde{\mathrm{F}}_{\mathrm{Sn}}\right)$ using the spherical fuzzy linguistic terms given in Tab. 1. Spherical Weighted Arithmetic Mean (SWAM) operator is used to aggregate decision matrix using Eqs. (20) and (21): 


$$
\begin{gathered}
\tilde{F}^{a g g}=S W A M_{w}\left(\tilde{F}_{S 1}, \ldots, \tilde{F}_{S n}\right)=w_{1} \tilde{F}_{S 1}+w_{2} \tilde{F}_{S 2}+\ldots+w_{n} \tilde{F}_{S n}=\left\{\left[1-\prod_{i=1}^{n}\left(1-\alpha_{\tilde{F}_{S i}}^{2}\right)^{w_{i}}\right]^{0.5},\right. \\
\left.\prod_{i=1}^{n} \beta_{\tilde{F}_{S i}}^{w_{i}},\left[\prod_{i=1}^{n}\left(1-\alpha_{\tilde{F}_{S i}}^{2}\right)^{w_{i}}-\prod_{i=1}^{n}\left(1-\alpha_{\tilde{F}_{S i}}^{2}-\gamma_{\tilde{F}_{S i}}^{2}\right)^{w_{i}}\right]^{0.5}\right\} \\
\tilde{F}^{a g g}=\left[\begin{array}{ccc}
\left(\alpha_{11}, \beta_{11}, \gamma_{11}\right) & \cdots & \left(\alpha_{1 m}, \beta_{1 m}, \gamma_{1 m}\right) \\
\vdots & \ddots & \vdots \\
\left(\alpha_{n 1}, \beta_{n 1}, \gamma_{n 1}\right) & \cdots & \left(\alpha_{n m}, \beta_{n m}, \gamma_{n m}\right)
\end{array}\right]
\end{gathered}
$$

Table 1: Linguistic scales and Spherical fuzzy numbers

\begin{tabular}{lll}
\hline Linguistic scale & Code & $(\alpha, \beta, \gamma)$ \\
\hline Absolutely more importance & AMI & $(0.9,0.1,0.1)$ \\
Very high importance & VHI & $(0.8,0.2,0.2)$ \\
High importance & HI & $(0.7,0.3,0.3)$ \\
Slightly more importance & SMI & $(0.6,0.4,0.4)$ \\
Equally importance & EI & $(0.5,0.5,0.5)$ \\
Slightly low importance & SLI & $(0.4,0.6,0.4)$ \\
Low importance & LI & $(0.3,0.7,0.3)$ \\
Very low importance & VLI & $(0.2,0.8,0.2)$ \\
Absolutely low importance & ALI & $(0.1,0.9,0.1)$ \\
\hline
\end{tabular}

Step 3: Criteria's entropies are used for determining their weights $\left(w_{j}\right)$. Divergence $\left(\operatorname{div}_{\mathrm{j}}\right)$ representing the intrinsic information of each criterion calculated through $\operatorname{div}_{\mathrm{j}}=1-\mathrm{EW}_{\mathrm{j}}$. Obtaining entropy weights by Eqs. (22) and (23):

$E W_{j}=\frac{1}{n} \sum_{i=1}^{n}\left[1-\frac{4}{5}\left(\left|\alpha_{i j}^{2}-\beta_{i j}^{2}\right|+\left|\gamma_{i j}^{2}-0.25\right|\right)\right]$

$w_{j}=\frac{d i v_{j}}{\sum_{j}^{m} d i v_{j}}$

Step 4: Simple additive weighting (SAW) method is operated to find the $S \tilde{A} \mathrm{~W}_{\mathrm{i}} \mathrm{SF}$ scores of each alternative based on the addition operation of SFSs in Section 3.1. The performance evaluations can be weighted as given in Eqs. (25) and (26). A defuzzification process of $S A W_{i}^{\text {def }}$ values as given in Eq. (27). If required, the alternatives can also be ranked in descending order of $S A W_{i}^{\text {def }}$ values after a defuzzification operation.

$$
\begin{aligned}
& S \tilde{A} \mathrm{~W}_{\mathrm{i}}=\sum_{j=1}^{m}\left(w_{j}\left\langle\alpha_{i j}, \beta_{i j}, \gamma_{i j}\right)\right)=\left\langle\alpha_{i}^{S A W}, \beta_{i}^{S A W}, \gamma_{i}^{S A W}\right\rangle \\
& w_{j}\left\langle\alpha_{i j}, \beta_{i j}, \gamma_{i j}\right\rangle=\left\{\left(1-\left(1-\alpha_{i j}^{2}\right)^{w_{j}}\right)^{\frac{1}{2}}, v_{i j}^{w_{j}},\left(\left(1-\alpha_{i j}^{2}\right)^{w_{j}}-\left(1-\alpha_{i j}^{2}-\gamma_{i j}^{2}\right)^{w_{j}}\right)^{\frac{1}{2}}\right\} \\
& \left\langle\alpha_{i 1}, \beta_{i 1}, \gamma_{i 1}\right\rangle \oplus\left\langle\alpha_{i 2}, \beta_{i 2}, \gamma_{i 2}\right\rangle=\left\{\left(\alpha_{i 1}^{2}+\alpha_{i 2}^{2}-\alpha_{i 1}^{2} \alpha_{i 2}^{2}\right)^{\frac{1}{2}}, \beta_{i 1} \beta_{i 2},\left(\left(1-\alpha_{i 2}^{2}\right) \gamma_{i 1}^{2}+\left(1-\alpha_{i 1}^{2}\right) \gamma_{i 2}^{2}-\gamma_{i 1}^{2} \gamma_{i 2}^{2}\right)^{\frac{1}{2}}\right\}
\end{aligned}
$$


$S A W_{i}^{d e f}=\left(\alpha_{i}^{S A W}-\gamma_{i}^{S A W}\right)^{2}-\left(\beta_{i}^{S A W}-\gamma_{i}^{S A W}\right)^{2}$

Step 5. Weighted product model (WPM) is performed on $F^{a g g}$ by taking $\mathrm{w}_{\mathrm{j}}$ into account for obtaining the $W \tilde{P} \mathrm{M}_{\mathrm{i}}$ of each alternative given in Eqs. (28) and (29). The exponentially weighted scores can be aggregated by performing the multiplication operation given in Eq. (30). If required, the alternatives can also be ranked in descending order of $W P W_{i}^{\text {def }}$ values after a defuzzification operation.

$$
\begin{aligned}
& W \tilde{P} \mathrm{M}_{\mathrm{i}}=\prod_{j=1}^{m}\left\langle\alpha_{i j}, \beta_{i j},\left.\gamma_{i j}\right|^{\mathrm{w}_{\mathrm{j}}}=\left\langle\alpha_{i}^{W P M}, \beta_{i}^{W P M}, \gamma_{i}^{W P M}\right\rangle\right. \\
& \left\langle\alpha_{i j}, \beta_{i j},\left.\gamma_{i j}\right|^{\mathrm{w}_{\mathrm{j}}}=\left\{\alpha_{i}^{w_{j}},\left(1-\left(1-\beta_{i}^{2}\right)^{w_{j}}\right)^{\frac{1}{2}},\left(\left(1-\beta_{i}^{2}\right)^{w_{j}}-\left(1-\beta_{i}^{2}-\gamma_{i}^{2}\right)^{w_{j}}\right)^{\frac{1}{2}}\right\}\right. \\
& \left\langle\alpha_{i 1}, \beta_{i 1}, \gamma_{i 1}\right\rangle \otimes\left\langle\alpha_{i 2}, \beta_{i 2}, \gamma_{i 2}\right\rangle=\left\{\alpha_{i 1} \alpha_{i 2},\left(\beta_{i 1}^{2}+\beta_{i 2}^{2}-\beta_{i 1}^{2} \beta_{i 2}^{2}\right)^{\frac{1}{2}},\left(\left(1-\beta_{i 2}^{2}\right) \gamma_{i 1}^{2}+\left(1-\beta_{i 1}^{2}\right) \gamma_{i 2}^{2}-\gamma_{i 1}^{2} \gamma_{i 2}^{2}\right)^{\frac{1}{2}}\right\}
\end{aligned}
$$

Step 6. SAW and WPM spherical fuzzy values are aggregated by employing a threshold number of $\delta$ representing their importance. To obtain the aggregated value of each alternative using Eq. (31):

$$
\tilde{Q}_{i}=\delta S \tilde{A} \mathrm{~W}_{\mathrm{i}}+(1-\delta) W \tilde{P} \mathrm{M}_{\mathrm{i}}=\left\langle\alpha_{i}, \beta_{i}, \gamma_{i}\right\rangle
$$

$$
\begin{aligned}
& \delta S \tilde{A} \mathrm{~W}_{\mathrm{i}}=\left\{\left(1-\left(1-\left(\alpha_{i}^{S A W}\right)^{2}\right)^{\delta}\right)^{\frac{1}{2}},\left(\beta_{i}^{S A W}\right)^{\delta},\left(\left(1-\left(\alpha_{i}^{S A W}\right)^{2}\right)^{\delta}-\left(1-\left(\alpha_{i}^{S A W}\right)^{2}-\left(\gamma_{i}^{S A W}\right)^{2}\right)^{\delta}\right)^{\frac{1}{2}}\right\} \\
&(1-\delta) W \tilde{P} \mathrm{M}_{\mathrm{i}}=\left\{\left(1-\left(1-\left(\alpha_{i}^{W P M}\right)^{2}\right)^{(1-\delta)}\right)^{\frac{1}{2}},\left(\beta_{i}^{W P M}\right)^{(1-\delta)},\left(\left(1-\left(\alpha_{i}^{W P M}\right)^{2}\right)^{(1-\delta)}\right.\right. \\
&\left.\left.-\left(1-\left(\alpha_{i}^{W P M}\right)^{2}-\left(\gamma_{i}^{W P M}\right)^{2}\right)^{(1-\delta)}\right)^{\frac{1}{2}}\right\}
\end{aligned}
$$

Step 7. SF values $\tilde{\mathrm{Q}}_{\mathrm{i}}$ are defuzzified and $Q_{i}$ crisp values are found by performing Eq. (32). Then, they are ranked in descending order.

$Q_{i}=\left(\alpha_{i}-\gamma_{i}\right)^{2}-\left(\beta_{i}-\gamma_{i}\right)^{2}$

If any alternatives have the same $Q_{i}$ values, their accuracy function values might be considered to break this tie. Accuracy function is $A c c_{i}=\alpha_{i}^{2}+\beta_{i}^{2}+\gamma_{i}^{2}$.

\section{A Case Study and Results}

\subsection{A Case Study of the Vietnamese SMEs}

The data was gathered in accordance with international payment systems through an online questionnaire survey of 5 specialists. The data collection process involved contacting regional universities qualified and experienced import-export industry managers and international economics researchers. One expert works for the Vietnam Trade Promotion Agency and Agency of Foreign Trade, two scholars work at foreign trade and international business universities, and two individuals with more than ten years of experience serving in the import-export sector from Ha Noi and Ho Chi Minh city, Vietnam.

To show the applicability of the proposed entropy-based SF-WASPAS methodology, the case study presented by [43] is analyzed. The goal of this decision problem is to find the most appropriate international payment alternative. In this study, four international payment methods and five main 
criteria with 22 sub-criteria are considered. Five DMs who were selected due to their expertise in international trade assessed four alternatives. The hierarchy of criteria and sub-criteria and four alternatives are presented in Fig. 3. The decision support model of SF-EW and WASPAS- SF is presented to find the optimal choice of international payment method alternatives. Additionally, a sensitivity analysis is performed to demonstrate the proposed method's dependability and applicability by examining ranking results obtained using alternative approaches.

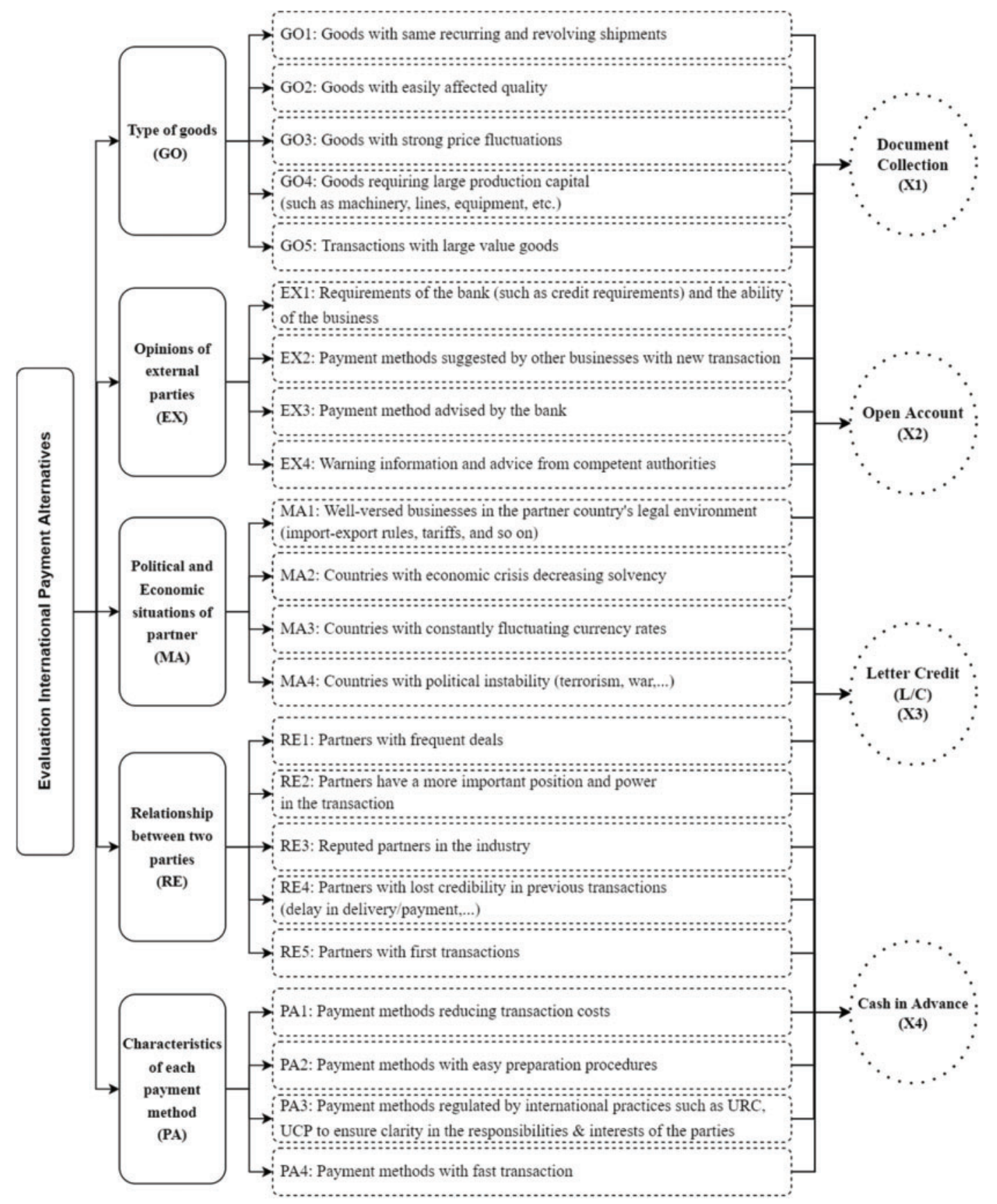

Figure 3: The hierarchical framework 


\subsection{Results Analysis}

First, the weights of these DMs who have different experience levels and positions are shown in Tab. 2. As an example, the calculation of weights of the $1^{\text {st }}$ expert (E1) is shown as follows:

Table 2: The weights of DMs

\begin{tabular}{|c|c|c|c|c|c|}
\hline Expert & $\mathrm{E} 1$ & $\mathrm{E} 2$ & E3 & $\mathrm{E} 4$ & E5 \\
\hline Years of Experience & 11 & 10 & 15 & 12 & 15 \\
\hline Education Level & MBA & MBA & Ph.D & Ph.D & MBA \\
\hline Positions & Manager & Policymaker & $\begin{array}{l}\text { Faculty } \\
\text { member }\end{array}$ & $\begin{array}{l}\text { Faculty } \\
\text { member }\end{array}$ & Manager \\
\hline $\begin{array}{l}\text { Linguistic } \\
\text { Assessment }\end{array}$ & EI & SMI & VHI & $\mathrm{HI}$ & LI \\
\hline SFNs & $\begin{array}{l}(0.5,0.5,0.5) \\
\lambda_{1}=0.192\end{array}$ & $\begin{array}{l}(0.6,0.4,0.4) \\
\lambda_{2}=0.215\end{array}$ & $\begin{array}{l}(0.8,0.2,0.2) \\
\lambda_{3}=0.246\end{array}$ & $\begin{array}{l}(0.7,0.3,0.3) \\
\lambda_{4}=0.233\end{array}$ & $\begin{array}{l}(0.3,0.7,0.3) \\
\lambda_{5}=0.115\end{array}$ \\
\hline
\end{tabular}

$$
\begin{aligned}
\lambda_{1} & =\frac{\left(\alpha_{e_{1}}+\gamma_{e_{1}}\left(\frac{\alpha_{e_{1}}}{\alpha_{e_{1}}+\beta_{e_{1}}}\right)\right)}{\sum_{e=1}^{5}\left(\alpha_{e_{1}}+\gamma_{e_{1}}\left(\frac{\alpha_{e_{1}}}{\alpha_{e_{1}}+\beta_{e_{1}}}\right)\right)} \\
& =\frac{\left(0.5+0.5\left(\frac{0.5}{0.5+0.5}\right)\right)}{\left(0.5+0.5\left(\frac{0.5}{0.5+0.5}\right)\right)+\left(0.6+0.4\left(\frac{0.6}{0.6+0.4}\right)\right)+\left(0.8+0.2\left(\frac{0.8}{0.8+0.2}\right)\right)+\left(0.7+0.3\left(\frac{0.7}{0.7+0.3}\right)\right)+\left(0.3+0.3\left(\frac{0.3}{0.3+0.7}\right)\right)} \\
& =\frac{0.75}{3.91}=0.192
\end{aligned}
$$

DMs evaluated the alternatives using the linguistic terms in terms of four attributes and give the alternative evaluation matrices $\left(F^{e 1}, F^{e 2}, F^{e 3}, F^{e 4}, F^{e 5}\right)$. After these linguistic terms are converted to corresponding SFNs, SWAM operator (Eq. 20) is implemented for aggregating evaluation criterion by criterion in Step 2. The objective weights of criteria are calculated by using the proposed entropybased approach. First, the entropy value of each criterion is computed by applying Eq. (22). Then, entropy is used in Eq. (23) for obtaining objective criteria weights. As an example, the entropy of GO is computed as follows: 


$$
\begin{aligned}
E W_{G O}= & \frac{1}{n} \sum_{i=1}^{n}\left[1-\frac{4}{5}\left(\left|\alpha_{11}^{2}-\beta_{11}^{2}\right|+\left|\gamma_{11}^{2}-0.25\right|\right)\right] \\
& =\frac{1}{4}\left[\left(1-\frac{4}{5}\left(\left|(0.717)^{2}-(0.284)^{2}\right|+\left|(0.289)^{2}-0.25\right|\right)\right)\right. \\
& +\left(1-\frac{4}{5}\left(\left|(0.722)^{2}-(0.295)^{2}\right|+\left|(0.304)^{2}-0.25\right|\right)\right) \\
& +\left(1-\frac{4}{5}\left(\left|(0.813)^{2}-(0.201)^{2}\right|+\left|(0.156)^{2}-0.25\right|\right)\right) \\
& \left.+\left(1-\frac{4}{5}\left(\left|(0.295)^{2}-(0.729)^{2}\right|+\left|(0.306)^{2}-0.25\right|\right)\right)\right]=0.472 \\
w_{G O}= & \frac{d i v_{j}}{\sum_{j}^{m} d i v_{j}}=\frac{1-E W_{j}}{\sum_{j}^{m} d i v_{j}}=\frac{1-0.472}{0.528+0.443+0.596+0.56+0.701}=0.187
\end{aligned}
$$

Entropy values of the remaining criteria and corresponding weights are given in Tab. 3. According to the objective weighting approach, the importance ranking of criteria is found as PA (Characteristics of each payment method) $>$ MA (Political and Economic situations of partner) $>$ RE (Relationship between two parties) $>$ EX (Opinions of external parties) $>$ GO (Type of goods) since the weights are found $24.8 \%$ for PA, $21.1 \%$ for MA, $19.8 \%$ for RE, $18.7 \%$ for GO and $15.7 \%$ for EX.

The weighted scores are calculated and then summed by performing Eq. (26). Tab. 4 gives the aggregated scores of alternatives which are represented as SFNs in the column of $S \tilde{A} \mathrm{~W}_{\mathrm{i}}$. Defuzzification of these numbers is made by using Eq. (27) and depicted in the column of $S A W_{i}^{\text {def }}$. Other exponentially weighted scores are calculated and then summed by performing Eq. (30). Tab. 4 presents the aggregated scores of alternatives which are represented as SFNs in the column of $W \tilde{P} M_{\mathrm{i}}$. Defuzzification of these numbers is made by using the same concept in Eq. (27) and depicted in the column of $W P M_{i}^{\text {def }}$. The alternatives can be ordered according to these values: X3 (Letters of credit method $)>$ X1 (Document collection method) $>$ X2 (Open Account method) $>$ X4 (Cash in Advance method).

As an example of obtaining defuzzified values of alternatives, $S A W_{i}^{\text {def }}$ and $W P M_{i}^{\text {def }}$ are given below:

$$
\begin{aligned}
& S A W_{i}^{\text {def }}=\left(\alpha_{i}^{S A W}-\gamma_{i}^{S A W}\right)^{2}-\left(\beta_{i}^{S A W}-\gamma_{i}^{S A W}\right)^{2}=(0.712-0.296)^{2}-(0.300-0.296)^{2}=0.172 \\
& W P M_{i}^{\text {def }}=\left(\alpha_{i}^{W P M}-\gamma_{i}^{W P M}\right)^{2}-\left(\beta_{i}^{W P M}-\gamma_{i}^{W P M}\right)^{2}=(0.695-0.308)^{2}-(0.323-0.308)^{2}=0.150
\end{aligned}
$$

By applying Eq. (31), $\tilde{Q}_{i}$ values are calculated as visualized in Fig. 4, and defuzzied values $\left(Q_{i}\right)$ which are calculated by Eq. (32).

\subsection{Sensitivity Analysis}

In this section, the authors proposed a sensitivity analysis to investigate the changes of the various sets of parameters $\delta$ in the WASPAS-SF model. Threshold $\delta$ representing the importance of these two scores $S \tilde{A} \mathrm{~W}_{\mathrm{i}}$ and $W \tilde{P} M_{\mathrm{i}}$ for finding the WASPAS-SF score of each alternative is employed. 


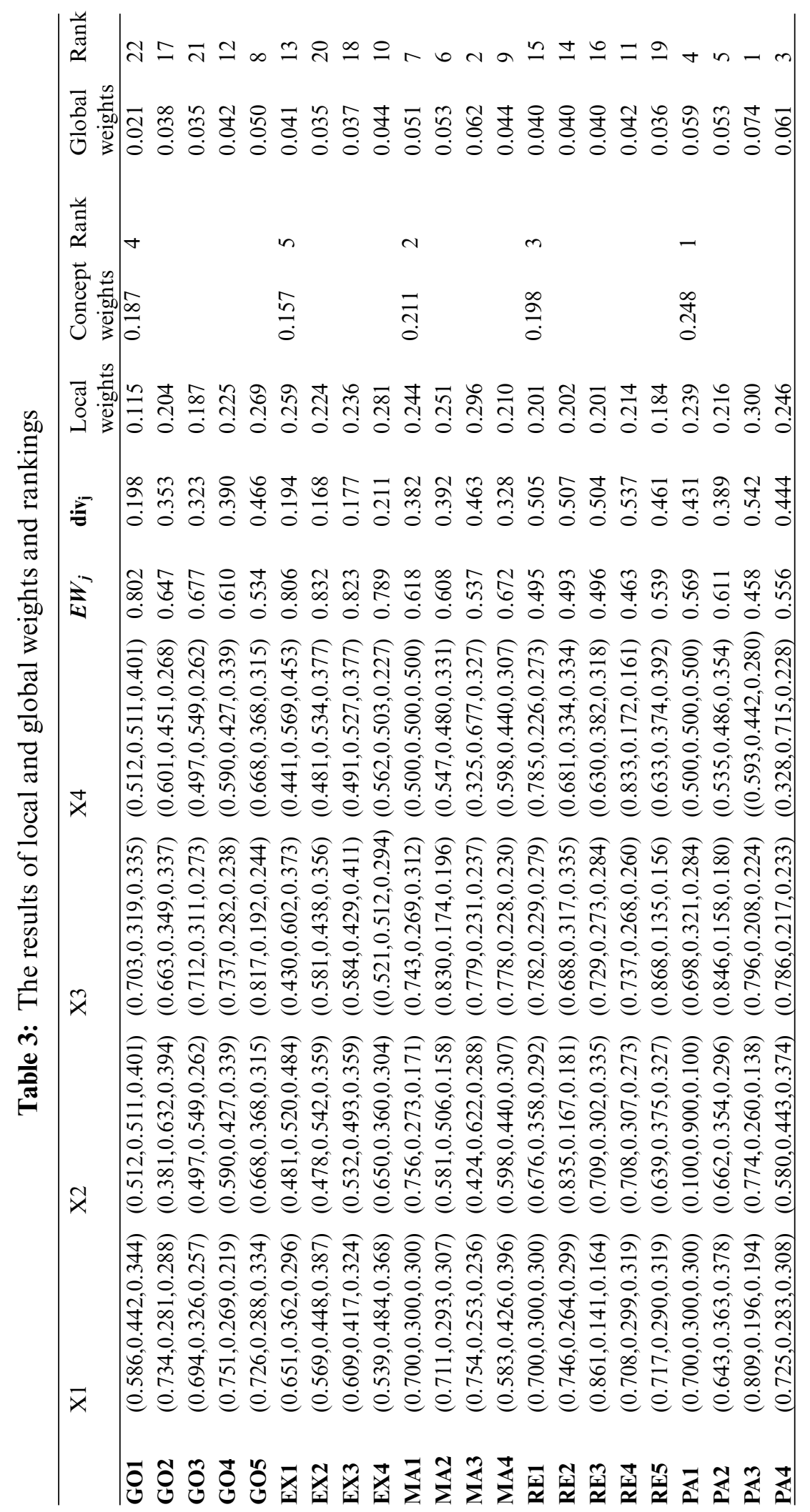


Table 4: Results of SAW and WPM

\begin{tabular}{llllll}
\hline & $S \tilde{A} \mathrm{~W}_{\mathrm{i}}$ & $S A W_{i}^{\text {def }}$ & $W \tilde{P} M_{\mathrm{i}}$ & $W P M_{i}^{\text {def }}$ & $\mathrm{Rank}$ \\
\hline $\mathrm{X} 1$ & $(0.711,0.300,0.297)$ & 0.172 & $(0.695,0.323,0.308)$ & 0.150 & 2 \\
$\mathrm{X} 2$ & $(0.626,0.413,0.294)$ & 0.096 & $(0.542,0.508,0.297)$ & 0.015 & 3 \\
$\mathrm{X} 3$ & $(0.748,0.265,0.266)$ & 0.233 & $(0.720,0.310,0.283)$ & 0.190 & 1 \\
$\mathrm{X} 4$ & $(0.581,0.451,0.341)$ & 0.046 & $(0.538,0.497,0.349)$ & 0.014 & 4 \\
\hline
\end{tabular}

Varying the $\delta$ values from 0 to 1 are considered to assess the sensitivity of the proposed model. First, if $\delta=0$, the results will be equal to the results of WPM, and then if $\delta=1$ is set, the results will be the same as the SAW result. As can be seen in Fig. 4, the rankings of alternatives for varying $\delta$ are not changed: $\mathrm{X} 3>\mathrm{X} 1>\mathrm{X} 2>\mathrm{X} 4$. Therefore, the proposed model is applicability and effectiveness.

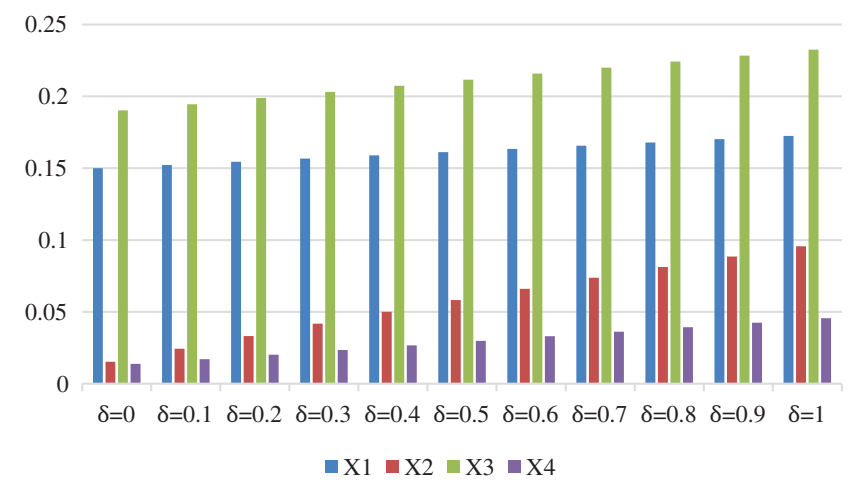

Figure 4: Final ranking of alternatives for sensitivity analysis

\section{Conclusions and Future Studies}

This study explores the aspects affecting choosing international payment methods of import and export SMEs in Vietnam. A hybrid MCDM approach of SF-EW, the WASPAS-SF was proposed for Vietnamese businesses to minimize risks when choosing payment methods in international transactions, considering qualitative and quantitative research methodologies. Five main criteria were considered in this research model, including Relationship between the two parties, Type of goods, The political and economic situation of the partner, Characteristics of each payment method, The opinions and requirements of external parties. The SF-EW, the WASPAS-SF results showed that L/C is the best choice of payment method for Vietnamese SMEs. This study aims to provide suggestions to develop Vietnam's import-export industry and Vietnam's international payment services. The main contributions are summarized as follows. First, robust integration of SF-EW and WASPAS-SF was proposed for the first time to support stakeholders of import-export SMEs in selecting international payment methods. An evaluation indicator system affecting the selection process of international payment methods was determined by experts' opinions and literature review. The SF-EW was utilized to calculate criteria weights under uncertain circumstances, then SF-WASPAS ranked the international payment methods. A case study was presented to test the feasibility of the proposed paradigm. Additionally, the combined model can be investigated in conjunction with other models to broaden the range of outcomes. The prescribed approach and outcomes in this study can inform similar 
international payment method selection processes in other nations and businesses. One of the study's limitations is that the evaluation process depends mainly on experts' opinions; thus, results are based on personal opinions, knowledge, and judgment. For avoiding this limitation, five experts were utilized to provide different preferences. Other multi-criteria evaluation techniques could be employed to achieve the same goal, and findings could be compared. The analysis's weakness could also be strengthened by including more quantitative evaluation criteria.

In terms of managerial implications that the current study implied, businesses must understand the nature of the commodities they sell to select the best IP solution. To reduce risks and damages in payments with international partners, companies must strengthen data capture on previous examples of hazards notified by authorities related to product categories identical to those of their firms. Aside from that, organizations must grasp and comprehend the foreign market's trading processes for specific items to properly comprehend their responsibilities, obligations, and rights in transaction strategies. Understanding such practical procedures would thus assist businesses in raising their awareness of the quality of goods to assure the issuing bank's capacity to pay. Through trade promotion events, create opportunities to contact and learn about overseas companies. The entire country's trade promotion operations are critical in supporting and promoting the development of export markets, including traditional markets, potential markets, and export markets.

To further elucidate this conceptual methodology, research international payment systems by distributing broader survey questions to import-export SMEs in Vietnam can signify avenues for future work. The combinations of the MCDM model and Partial Least Squares Structural Equation Modeling (PLS-SEM) [44] in the subsequent stage are recommended to highlight the gap in the relative relevance of criteria linked to international payment methods in international trade operations. Methodologies can be utilized to analyze international payment method selection in other countries and additional criteria. This study demonstrates how combining MCDM based Spherical fuzzy set might result in a more successful evaluation model. Their results can be compared to prior studies' results which can be expanded in future studies by assessing the relative performance of new MCDM techniques that incorporate emerging modern fuzzy extensions, such as spherical fuzzy sets, intuitionistic fuzzy sets, and hesitant fuzzy sets.

Funding Statement: This research was funded by FPT University, Vietnam.

Conflicts of Interest: The authors declare that they have no conflicts of interest to report regarding the present study.

\section{References}

[1] T. T. Tran, T. Q. A. Ngo, T. N. A. Cung, T. G. Nguyen, D. D. Vu et al., "Influencing factors of the international payment service quality at joint stock commercial bank for investment and development of Vietnam," Journal of Asian Finance, Economics and Business, vol. 7, no. 10, pp. 241-254, 2020.

[2] Q. T. Tran, M. U. Tran and X. T. Le, "Factors affecting satisfaction of customers' savings deposit in the context of covid-19: Evidence from Vietnamese commercial banks," Journal of Asian Finance, Economics and Business, vol. 7, no. 10, pp. 369-376, 2020.

[3] Y. C. Wang, J. J. Tsai and X. Chen, "The impact of RMB internationalization and international situations on China's foreign exchange market: Dynamic linkages between USD/CNY and SDR/CNY," Emerging Markets Finance and Trade, vol. 57, no. 5, pp. 1437-1454, 2021.

[4] C. Nguyen, D. Dinh and T. Doan, "The determinants of the choices of payment methods for goods and services transaction in Vietnam," International Journal of Applied Science, vol. 1, no. 2, pp. 84-92, 2018. 
[5] N. P. T. Hang and M. L. T. Nguyen, "Technological factors affecting the profitability of commercial banks in Vietnam," Academy of Accounting and Financial Studies Journal, vol. 23, no. 4, pp. 1-16, 2019.

[6] R. Bollen, "The history and operation of international payment system," Journal of Banking and Finance Law and Practice, vol. 18, no. 27, pp. 1-33, 2007.

[7] A. Ulutaş, G. Popovic, D. Stanujkic, D. Karabasevic, E. K. Zavadskas et al., "A new hybrid MCDM model for personnel selection based on a novel grey PIPRECIA and grey OCRA methods," Mathematics, vol. 8, no. 10, pp. 1-14, 2020.

[8] R. Wang, X. Li and C. Li, "Optimal selection of sustainable battery supplier for battery swapping station based on triangular fuzzy entropy-MULTIMOORA method," Journal of Energy Storage, vol. 34, no. 8, pp. 102013, 2021.

[9] S. Chakraborty and E. K. Zavadskas, "Applications of WASPAS method in manufacturing decision making," Informatica (Netherlands), vol. 25, no. 1, pp. 1-20, 2014.

[10] T. Wang, "The interactive trade decision-making research: An application case of novel hybrid MCDM model," Economic Modelling, vol. 29, no. 3, pp. 926-935, 2012.

[11] N. Chiao and C. H. Y. Li, "A study of A/R collection for IC design industry in Taiwan using fuzzy MCDM methodology," in PICMET'07-2007 Portland Int. Conf. on Management of Engineering \& Technology, Portland, OR, USA, pp. 1248-1255, 2007.

[12] E. Surucu-balci, "Blockchain adoption in the maritime supply chain: Examining barriers and salient stakeholders in containerized international trade," Transportation Research Part E: Logistics and Transportation Review, vol. 156, no. 2, pp. 102539, 2021.

[13] I. Lescauskiene, R. Bausys, E. K. Zavadskas and B. Juodagalviene, "VASMA weighting: Survey-based criteria weighting methodology that combines entropy and WASPAS-SVNS to reflect the psychometric features of the VAS scales," Symmetry, vol. 12, no. 10, pp. 1-20, 2020.

[14] F. Kutlu Gundogdu and C. Kahraman, "Extension of WASPAS with spherical fuzzy sets," Informatica (Netherlands), vol. 30, no. 2, pp. 269-292, 2019.

[15] E. Ayyildiz and A. Taskin Gumus, "A novel spherical fuzzy AHP-integrated spherical WASPAS methodology for petrol station location selection problem: A real case study for İstanbul," Environmental Science and Pollution Research, vol. 27, no. 29, pp. 36109-36120, 2020.

[16] M. Keshavarz-ghorabaee, M. Amiri and M. Hashemi-tabatabaei, "A new decision-making approach based on fermatean fuzzy sets and WASPAS for green construction supplier evaluation," Mathematics, vol. 8, no. 12, pp. 2202, 2020.

[17] P. H. Nguyen, J. F. Tsai, T. T. Dang, M. H. Lin, H. A. Pham et al., "A hybrid spherical fuzzy MCDM approach to prioritize governmental intervention strategies against the covid-19 pandemic: A case study from Vietnam," Mathematics, vol. 9, no. 20, pp. 1-28, 2021.

[18] M. Gul and M. F. Ak, "A modified failure modes and effects analysis using interval-valued spherical fuzzy extension of TOPSIS method: Case study in a marble manufacturing facility," Soft Computing, vol. 25, no. 8, pp. 6157-6178, 2021.

[19] I. M. Sharaf and E. A. H. A. Khalil, "A spherical fuzzy TODIM approach for green occupational health and safety equipment supplier selection," International Journal of Management Science and Engineering Management, vol. 16, no. 1, pp. 1-13, 2021.

[20] M. Bakır, Ş. Akan and E. Özdemir, "Regional aircraft selection with fuzzy Piprecia and fuzzy Marcos: A case study of the Turkish airline industry," Facta Universitatis, Series: Mechanical Engineering, vol. 19, no. 3, pp. 423, 2021. 
[21] K. P. Fuller and M. B. Glatzer, "Method-of-payment choice for international targets," Advances in Financial Economics, vol. 8, pp. 47-64, 2003.

[22] A. Hoefele, T. Schmidt-Eisenlohr and Z. Yu, "Payment choice in international trade: Theory and evidence from cross-country firm-level data," Canadian Journal of Economics, vol. 49, no. 1, pp. 296-319, 2016.

[23] T. Binet, P. Failler, P. N. Chavance and M. A. Mayif, "First international payment for marine ecosystem services: The case of the Banc d'Arguin National Park, Mauritania," Global Environmental Change, vol. 23, no. 6, pp. 1434-1443, 2013.

[24] S. Hwang and H. Im, "Why did the terms of payment in international trade change so much?," Applied Economics Letters, vol. 26, no. 7, pp. 576-581, 2019.

[25] J. Zhou and Y. Y. Hang, "International payment risk management of private small and medium-sized enterprises from a cultural value perspective: A case study in Zhejiang, China," in 2011 Int. Conf. on Electronics, Communications and Control (ICECC), Ningbo, China, pp. 3218-3223, 2011.

[26] U. Milkau, "International payments: Current alternatives and their drivers," Journal of Payments Strategy and Systems, vol. 13, no. 3, pp. 201-216, 2019.

[27] S. Hwang and H. Im, "Why did the terms of payment in international trade change so much?," Applied Economics Letters, vol. 26, no. 7, pp. 576-581, 2019.

[28] L. Yang, "Research on the comparison and selection strategy of the payment modes in international trade," in 2nd Int. Conf. on Management Science and Innovative Education, Sanya, China, Atlantis Press, 2016.

[29] K. Turkcan, "Evolving patterns of payment methods in Turkish foreign trade," World Journal of Applied Economics, vol. 65410, pp. 1-67, 2015.

[30] V. Torra, "Hesitant fuzzy sets," International Journal of Intelligent Systems, vol. 25, no. 6, pp. 529-539, 2010.

[31] C. J. Petersen, "Getting Paid for Your Exports: Payment Options for International Transactions: International Trade Blog," 2009. [Online]. Available: https://www.shippingsolutions.com/blog/payment-optionsfor-international-transactions-2.

[32] J. A. A. Agbonika, "Methods of international trade and payments: The Nigerian perspective," Global Journal of Politics and Law Research, vol. 3, no. 1, pp. 21-60, 2015.

[33] R. Becker, "7 Factors for Determining the Right Method of Payment for Your Exports: International Trade Blog,” 2014. [Online]. Available: https://www.shippingsolutions.com/blog/seven-factors-for-determiningthe-right-method-of-payment-for-your-exports.

[34] L. Delaney, "What Method of Payment to Choose for Imports: The Balance Small Business," 2019. [Online]. Available: https://www.thebalancesmb.com/how-to-choose-animport-payment-method1953391.

[35] H. Kristjánsdóttir, P.Ö. Guðlaugsson, S. Guðmundsdóttir and G. D. Aðalsteinsson, "Hofstede national culture and international trade," Applied Economics, vol. 49, no. 51, pp. 5792-5801, 2017.

[36] T. Susmus and S. O. Baslangic, "The new payment term BPO and its effects on Turkish international business," Procedia Economics and Finance, vol. 33, no. 15, pp. 321-330, 2015.

[37] K. P. Fuller and M. B. Glatzer, "Method-of-payment choice for international targets," Advances in Financial Economics, vol. 8, pp. 47-64, 2003.

[38] H. Y. Joo and D. J. Lee, "A study on the prediction model for international trade payment using logistic regression," Journal of Korea Trade, vol. 25, no. 2, pp. 111-133, 2021.

[39] H. Alavi, "mitigating the risk of fraud in documentary letters of credit," Baltic Journal of European Studies, vol. 6, no. 1, pp. 139-156, 2016.

[40] F. Kutlu Gündoğdu and C. Kahraman, "A novel spherical fuzzy analytic hierarchy process and its renewable energy application," Soft Computing, vol. 24, no. 6, pp. 4607-4621, 2020.

[41] A. Aydo and S. Gül, "A novel entropy proposition for spherical fuzzy sets and its application in multiple attribute decision - making,” International Journal of Intelligent Systems, vol. 35, no. 9, pp. 1354-1374, 2020. 
[42] Z. Turskis, E. K. Zavadskas, J. Antucheviciene and N. Kosareva, "A hybrid model based on fuzzy AHP and fuzzy WASPAS for construction site selection," International Journal of Computers, Communications and Control, vol. 10, no. 6, pp. 873-888, 2015.

[43] A. Aydoğdu and S. Gül, "A novel entropy proposition for spherical fuzzy sets and its application in multiple attribute decision-making," International Journal of Intelligent Systems, vol. 35, no. 9, pp. 1354-1374, 2020.

[44] P. H. Nguyen, J. F. Tsai, M. H. Lin and Y. C. Hu, "A hybrid model with spherical fuzzy-AHP, PLS-SEM and ANN to predict vaccination intention against COVID-19," Mathematics, vol. 9, no. 23, pp. 1-26, 2021. 